\title{
The solution is in the future, but hopefully it won't always be
}

\author{
Ourania Preventza, MD, ${ }^{\mathrm{a}}$ and Joseph S. Coselli, $\mathrm{MD}^{\mathrm{b}}$
}

\footnotetext{
From the ${ }^{\mathrm{a} D i v i s i o n}$ of Cardiothoracic Surgery, Baylor College of Medicine; and the ${ }^{\mathrm{b}}$ Division of Cardiovascular Surgery, Texas Heart Institute, Houston, Tex.

Disclosures: O.P. is a consultant for Medtronic and WL Gore \& Associates. J.S.C. participates in clinical research trials conducted by GlaxoSmithKline, Edwards Lifesciences, and Bolton Medical; consults for, receives royalties and a departmental educational grant from, and participates in clinical trials for Vascutek Terumo; consults and participates in clinical trials for Medtronic, Inc; and consults and participates in clinical trials for WL Gore \& Associates.

Received for publication July 11, 2016; accepted for publication July 12, 2016; available ahead of print Aug 18 , 2016.

Address for reprints: Ourania Preventza, MD, BCM 390, One Baylor Plaza, Houston, TX 77030 (E-mail: opsmile01@aol.com).

J Thorac Cardiovasc Surg 2016;152:1289-90

$0022-5223 / \$ 36.00$

Copyright (c) 2016 by The American Association for Thoracic Surgery

http://dx.doi.org/10.1016/j.jtcvs.2016.07.036
}

Zhang and colleagues ${ }^{1}$ present a systematic review and meta-analysis of the literature regarding aortic reintervention after thoracic endovascular aortic repair (TEVAR) for dissection, an interesting and timely subject, given the wide availability of endovascular technology today. The authors evaluated 27 studies that included data from 2029 TEVAR cases of 2403 aortic dissection cases with a mean follow-up of 34 months. The most common reasons for reintervention were type I endoleak $(35.2 \%)$, new dissection $(14.4 \%)$, and persistent false-lumen perfusion (9.3\%).

Although Zhang and colleagues ${ }^{1}$ used only 2 databases to identify published studies, they should be congratulated for addressing an evolving and crucial topic. The purpose of a meta-analysis is to aggregate enough data from underpowered studies to draw meaningful conclusions. The fact that the authors had to combine data on 2 substantially different pathologies (acute and chronic type B aortic dissection) suggests there are not enough data to draw robust conclusions.

In a meta-analysis by Moulakakis and colleagues ${ }^{2}$ regarding acute complicated type B aortic dissection, 2531 patients treated with TEVAR had a pooled 30-day or in-hospital mortality rate of $7.3 \%$; in comparison, the mortality rate was $2.4 \%$ for 2347 patients treated with conservative medical management for uncomplicated acute type $\mathrm{B}$ aortic dissection in 2347 patients and 19\% for 1276 patients treated with open surgical repair. Patients treated with TEVAR appeared to have more favorable outcomes regarding aortic remodeling and aortic-specific survival than those treated with medical therapy alone. That report emphasized the need for randomized trials.

The Investigation of Stent Grafts in Aortic Dissection With Extended Length of Follow-up (INSTEAD-XL) trial retrospectively analyzed data from 140 patients with stable type B aortic dissection who were randomly assigned to optimal medical treatment and $\operatorname{TEVAR}(n=72)$ or optimal medical treatment alone $(\mathrm{n}=68)$ for aorta-specific,

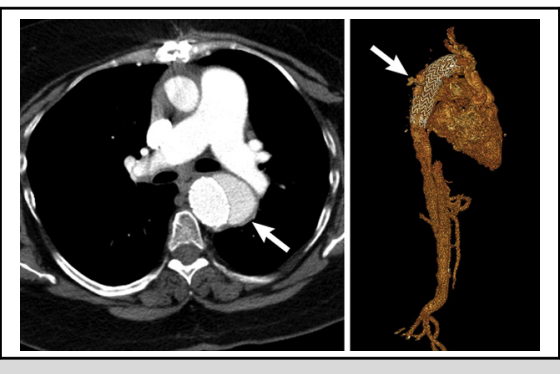

Retrograde filling of false lumen after TEVAR for acute type B aortic dissection.

\section{Central Message}

The industry should use an engineering perspective to address problems by developing new technologies instead of adapting existing ones.

See Article page 1279.

all-cause outcomes, and disease progression 5 years after the index procedure. ${ }^{3}$ The results suggested that adding TEVAR to optimal medical treatment improves 5-year aorta-specific survival and delays disease progression. ${ }^{3}$ The 1-year results from the Acute Dissection Stentgraft or Best Medical Treatment (ADSORB) trial of the GORE TAG (WL Gore \& Associates, Flagstaff, Ariz) stent graft for acute uncomplicated type B aortic dissection showed that placing a stent-graft induces thrombosis of the false lumen and reduction of its diameter. ${ }^{4}$

According to the 2014 European Guidelines ${ }^{5}$ for acute uncomplicated type B aortic dissection, medical therapy is always recommended (class I, level of evidence $\mathrm{C}$ ), but TEVAR should be considered (class IIa, level of evidence B). In complicated aortic dissection, TEVAR is recommended (class I, level of evidence C), but surgery may be considered (class IIb, level of evidence C).

Until recently, many of the acute and chronic dissections in the United States were treated with endovascular procedures performed off-label. Despite the previously described results ${ }^{3,4}$ and US Food and Drug Administration approval of devices for treating aortic dissection, the optimal therapy paradigm has not been identified yet. The devices used today are slight modifications of devices designed to perform a different function in another segment of the thoracic aorta.

Zhang and colleagues ${ }^{1}$ mention a high proximal endoleak rate of $35.2 \%$, which suggests that we are applying a technology that was designed for another disease process and that most of the patients do not have suitable anatomy for TEVAR. The number of patients who would have been 
stable without the need for initial intervention remains unknown.

The long-term results of open surgical reintervention in a chronic type B aortic dissection are acceptable. In a propensity-adjusted analysis ${ }^{6}$ of data from 122 patients who underwent open repair or TEVAR for chronic type B aortic dissection, open repair was more effective, and TEVAR was associated with a higher rate of treatment failure. These findings suggest 2 important points: Early endovascular therapy for acute dissection seems to be intended to prevent future surgical procedures, even though such procedures have good results and current device designs need to be modified.

It is important for the industry to take a fresh look from an engineering point of view and develop technology that addresses specific problems, instead of adapting existing technology that was designed to address a different problem.

\section{References}

1. Zhang L, Zhao Z, Chen Y, Sun Y, Bao J, Jing Z, et al. Re-intervention after endovascular repair for aortic dissection: a systematic review and meta-analysis. J Thorac Cardiovasc Surg. 2016;152:1279-88.e3.

2. Moulakakis KG, Mylonas SN, Dalainas I, Kakisis J, Kotsis T, Liapis CD. Management of complicated and uncomplicated acute type B dissection. A systematic review and meta-analysis. Ann Cardiothorac Surg. 2014;3:234-46.

3. Nienaber CA, Kische S, Rousseau H, Eggebrecht H, Rehders TC, Kundt G, et al. Endovascular repair of type B aortic dissection: long-term results of the randomized investigation of stent grafts in aortic dissection trial. Circ Cardiovasc Interv. 2013;6:407-16.

4. Brunkwall J, Kasprzak P, Verhoeven E, Heijmen R, Taylor P, Trialists A, et al. Endovascular repair of acute uncomplicated aortic type B dissection promotes aortic remodelling: 1 year results of the ADSORB trial. Eur J Vasc Endovasc Surg. 2014; 48:285-91.

5. Erbel R, Aboyans V, Boileau C, Bossone E, Bartolomeo RD, Eggebrecht H, et al. 2014 ESC Guidelines on the diagnosis and treatment of aortic diseases: Document covering acute and chronic aortic diseases of the thoracic and abdominal aorta of the adult. The Task Force for the Diagnosis and Treatment of Aortic Diseases of the European Society of Cardiology (ESC). Eur Heart J. 2014;35:2873-926.

6. van Bogerijen GH, Patel HJ, Williams DM, Yang B, Dasika NL, Eliason JL, et al. Propensity adjusted analysis of open and endovascular thoracic aortic repair for chronic type B dissection: a twenty-year evaluation. Ann Thorac Surg. 2015;99:1260-6. 